\title{
Thermo-structural Analysis of Steel-Composite Wall Nozzle
}

\author{
Ahmed R. Gomaa and Hai Huang
}

\begin{abstract}
Studying of the thermo-structural response of steel-composite rocket nozzle is carried out using ANSYS. A validation of ANSYS for thermal and structural analysis is done first for simple problems, then the analysis done with the nozzle. The result of thermal analysis shows that thermal loads have a great effect in generating a huge amount of stresses on the nozzle structure (more than $60 \%$ from the total stresses on the nozzle). The convictive heat transfer coefficient has a great effect on the temperature transferred to the nozzle wall. The composite material resists temperature augmentation, $s o$ it is regarded as a thermal protection material.
\end{abstract}

Index Terms-Thermo-structural analysis, composite, nozzle, ANSYS.

\section{INTRODUCTION}

Nozzle design is an iterative procedure in which aerodynamic, thermodynamic, structural, and fabrication considerations are handled within the constraints to produce a preliminary nozzle design. Steel is the basic structural material of Rocket Motor (RM) nozzles used for many years. Composite materials are beginning to be used in the aerospace industry because of superior material properties of composites over metals.

The thermal design objective is to sustain the nozzle internal contour and to limit the temperature of the structure to suitable levels. The structural mechanics design objectives are to configure the basic structural framework that will assist the applied loads and supports the insulators and liners to carry the nozzle loads.

ANSYS is one of the most common FEM codes, which is a complete general-purpose FEM code and a significant tool to design and analysis the aerospace structures. In this work, ANSYS is used for analyzing the thermo-structural analysis for RM nozzle made of conventional and composite material.

The analyzed nozzle consists of 3 main parts (steel-composite material-graphite insert for throat) loaded internally thermally and mechanically by temperature and pressure produced from combustion gases. The nozzle prevent from moving in all directions at the conjunction with the motor case. The firing duration is 7 seconds the following assumptions considered:

1) The bonding between materials is perfect.

2) The composite material properties only do not change with temperature.

Manuscript received August 16, 2016; revised October 13, 2016

Ahmed R. Gomaa is with School of Astronautics, Beihang University (BUAA), Beijing 100083, China (e-mail: ragabeta@ yahoo.com).

Hai Huang is with the Department of Astronautics, Beihang University (BUAA), Beijing 100083, China (e-mail: hhuang@buaa.edu.cn).
3) The radiation effect in thermal analysis is neglected.

4) No large deflections in structure.

A lot of works discussed the techniques in the assessment of the thermo-structural behavior of structures. Mukherjee and Sinha [1] used the FEM to analyze the thermo-structural response of rotationally symmetric multidirectional fibrous composite structures; a classic convergent-divergent nozzle uncooled made from composite material is analyzed. A. Zayed [2] built a finite element code for thermal and structural analysis of axisymmetric rocket nozzles made of composite materials with non-linear thermal and mechanical properties. A case study is chosen to be analyzed using the built code. The efficiency of the built code had been proven by the good agreement with results obtained from the validated finite element code, MARC, and from experimental results. E.V.Morozov, and J. Beaujardiere [3] used ADINA to illustrate the uncoupled dynamic thermo-structural response of a RM nozzle with composite throat. It is shown that the solution oscillates narrowly about the quasi-static solution. Francisco Alhama, Antonio Campo [4] presents a robust computational method called the network simulation method (NSM) that is representative for the numerical prediction of spatio-temporal temperatures in multi-layered composite walls in regular coordinate systems. Chang and Kutlu [5] study the response of composite cylindrical shells exposed to out-of-plane loadings experiencing large deformations. Prediction of the mechanical behavior of structures is done using developed analytical model, through post failure to final collapse. The developed model is created by FEM code based on the updated lagrangian formulation. Tsung-Chien Chen, and Chiun-Chien Liu [6] presented an analytical method for thermal design of the protection layer in the solid rocket motor by simulating the measured temperature on throat-insert of the nozzle to estimate the heat flux in the inner wall on-line with accuracy. The thermo-structural transient response of a composite rocket nozzle using a thin protective layer was predicted using FEM by Vandenboom and Heister [7], and a variety of structural and thermal results are presented for both the substrate and the protective layer. Cozart and Hsivakumar [8] performed a finite element axisymmetric stress analysis of a 3-D braided perform ablative composite rocket nozzle, including a material ablation study. In the work of Yoo et al. [9], a kick motor nozzle made from reinforced composites was subjected to thermo-elastic analysis following the development of a material model used to homogenize various 3-D reinforcement architectures. Kumar et al. [10] carry out an extensive thermo-structural analysis of composite structures, including temperature dependent properties, and mechanical, thermal, and thermo-chemical loads, and 
performed a coupled thermo-structural analysis for a SRM nozzle with different orthotropic and isotropic materials.

A validation of ANSYS for thermal and structural analysis is done, first, for simple problems, and then the analysis is carried out on the nozzle. The thermal and structural results are discussed for the instants of 1 and 7 seconds from firing duration, and final conclusions from these results analyzed.

\section{VALidATION OF THE ANSYS Finite ElEMENT CODE}

Before any major analyses were done using ANSYS, a validation process was carried out to establish the thermo-structural capabilities of the program. In essence, the procedure involved the comparison of results numerically derived by ANSYS, to those obtained from an analytical solution for a problem as similarly as possible (geometrically) to the nozzle in general. The validation is carried out in both thermal and structural analysis on a hollow cylinder (axisymmetric).

\section{A. Stress Analysis of Hollow Cylinder under Structural Load}

This sample problem is a simple configuration to be used for verification of stress analysis of ANSYS compared to the analytical solution [11].The model of sample problem is shown in Fig. 1, which represents a simple ring loaded by pressure on its internal surface.

The material of this model has Young`s modulus $\mathrm{E}=$ 1 .E +7 and Poisson`s ratio $v=0.3$, the applied pressure has the unit value. The ring is clamped at $y=0$ and $y=0.2$, the type of used element is (plane 55) from ANSYS library.

The results are compared with the exact solution as illustrated in Table I.

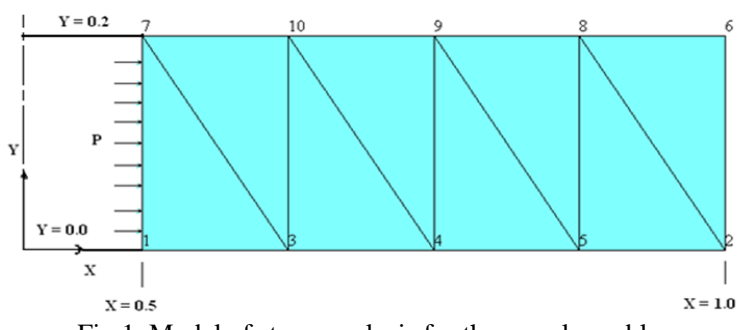

Fig.1. Model of stress analysis for the sample problem.

TABLE I: COMPARISON OF RESULTS OF ANSYS AND ANALYTICAL SOLUTION

\begin{tabular}{|c|c|c|c|c|c|c|}
\hline $\mathrm{X}$ & & $\varepsilon_{\mathrm{x}}$ & $\varepsilon_{\mathrm{z}}$ & $\sigma_{\mathrm{x}}$ & $\sigma_{\mathrm{z}}$ & \multirow{2}{*}{ Error $\%$} \\
\hline \multirow{2}{*}{0.5} & ANSYS & $-0.15579 \mathrm{E}-06$ & $0.19044 \mathrm{E}-06$ & -0.99845 & 1.6648 & \multirow{2}{*}{$0.11 \%$} \\
\cline { 2 - 6 } & Analytical & $-0.1560 \mathrm{E}-06$ & $0.19066 \mathrm{E}-06$ & -1.00000 & 1.66666 & \\
\hline \multirow{2}{*}{0.625} & ANSYS & $-0.93512 \mathrm{E}-07$ & $0.12818 \mathrm{E}-06$ & -0.51935 & 1.1859 & \multirow{2}{*}{$0.06 \%$} \\
\cline { 2 - 6 } & Analytical & $-0.9360 \mathrm{E}-07$ & $0.12826 \mathrm{E}-06$ & -0.52000 & 1.18666 & \\
\hline \multirow{2}{*}{0.75} & ANSYS & $-0.59665 \mathrm{E}-07$ & $0.94332 \mathrm{E}-07$ & -0.25895 & 0.92564 & \multirow{2}{*}{$0.03 \%$} \\
\cline { 2 - 6 } & Analytical & $-0.5970 \mathrm{E}-07$ & $0.94370 \mathrm{E}-07$ & -0.259259 & 0.92592 & \\
\hline \multirow{2}{*}{0.875} & ANSYS & $-0.39246 \mathrm{E}-07$ & $0.73916 \mathrm{E}-07$ & -0.10187 & 0.76860 & \multirow{2}{*}{$0.014 \%$} \\
\cline { 2 - 6 } & Analytical & $-0.3926 \mathrm{E}-07$ & $0.73931 \mathrm{E}-07$ & -0.102040 & 0.76871 & \\
\hline \multirow{2}{*}{1.0} & ANSYS & $-0.25989 \mathrm{E}-07$ & $0.60660 \mathrm{E}-07$ & $0.1082 \mathrm{E}-03$ & 0.66664 & \multirow{2}{*}{$0.003 \%$} \\
\cline { 2 - 6 } & Analytical & $-0.2600 \mathrm{E}-07$ & $0.60666 \mathrm{E}-07$ & 0.000 & 0.66666 & \\
\hline
\end{tabular}

\section{B. Transient Thermal Stress Analysis}

This problem is a thick cylinder heated by convection on the internal surface Fig. 2. Boundary conditions and material properties were selected such that an exact analytical solution is obtainable for comparison [13] and shown in Table II.
Convection at internal surface takes place from a fluid having bulk temperature of $373 \mathrm{~K}$. results is calculated during time of $200 \mathrm{sec}$ by incremental time steps.

The model is discretized into finite elements as shown in Fig. 2. The model consists of 231 nodes and 200 elements.

\begin{tabular}{lc} 
TABLE II: MATERIAL PROPERTIES FOR SAMPLE PROBLEM \\
\hline \multicolumn{1}{c}{ Parameter } & value \\
Density $\left[\mathrm{Kg} / \mathrm{m}^{3}\right]$ & 7850 \\
Specific heat $[\mathrm{J} / \mathrm{kg} . \mathrm{k}]$ & 410 \\
Thermal conductivity [W/m.k] & 60.5 \\
\hline \hline
\end{tabular}
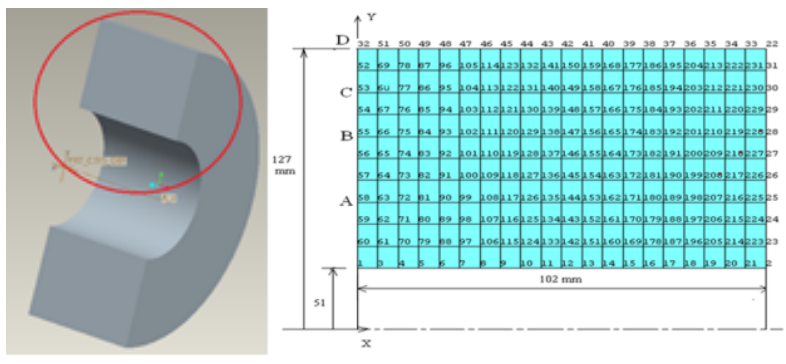

Fig. 2. Model of the sample problem: Dimension \& discretization.

This model is fed by bulk fluid temperature of $373 \mathrm{k}$ at its internal surface; the structure has initial (reference) temperature of $273 \mathrm{k}$. The forced convective coefficient is $864.7 \mathrm{~W} / \mathrm{m} 2 . \mathrm{k}$. The time interval from 0 to 200 seconds is divided into incremental time steps. Three different time steps are used in this problem; 5,10and 20 seconds.

Fig. 3 shows the history changes in the temperature of a node on the external surface due to change of incremental time. It is observed that the smallest increment of time (5 seconds) has given smaller error compared to analytical solution.

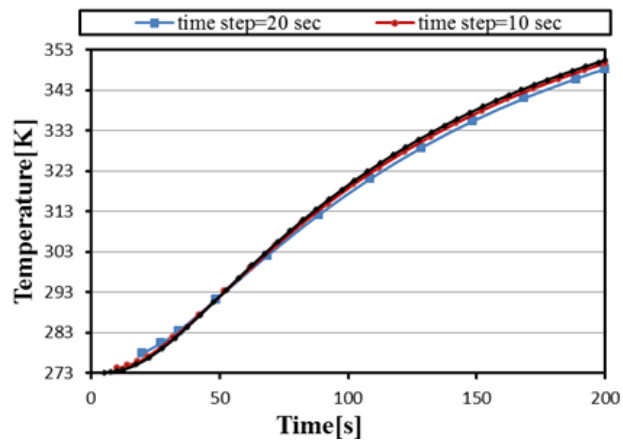

Fig. 3. Temperature history on the external surface for different incremental times.

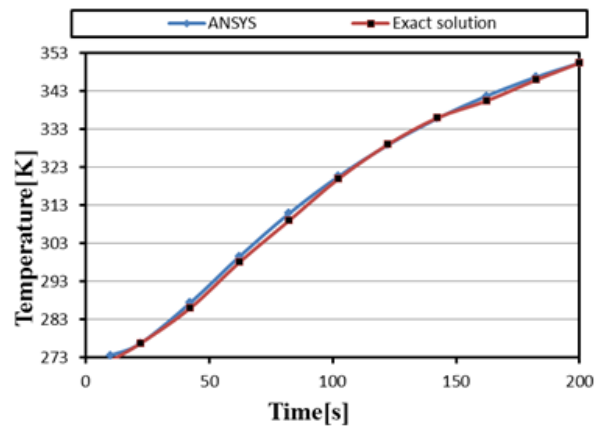

Fig. 4. Exact and ANSYS solutions of the sample problem for time step=5s.

The temperature history of the external surface obtained as 
output of ANSYS is compared to the analytical solution as illustrated in Fig. 4. Agreement of results indicates the efficiency of ANSYS.

Fig. 5, 6. Shows that the difference between the internal surface and external surface temperatures decreases by time increasing, it means that, the temperature profile decreases through the time.

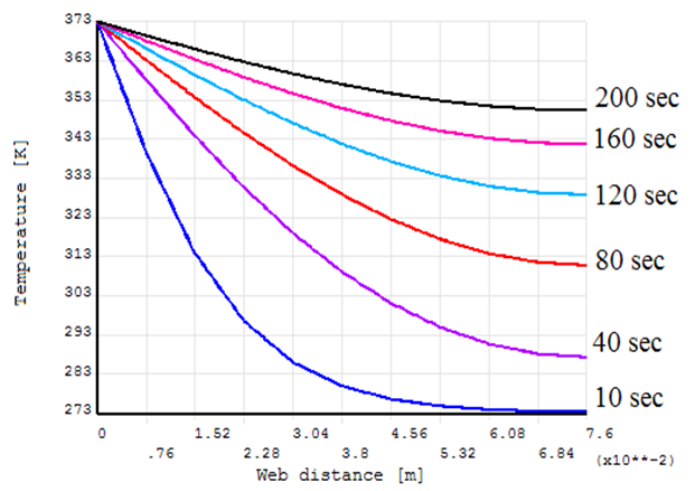

Fig. 5. Temperature history across the web through the total time (200sec).

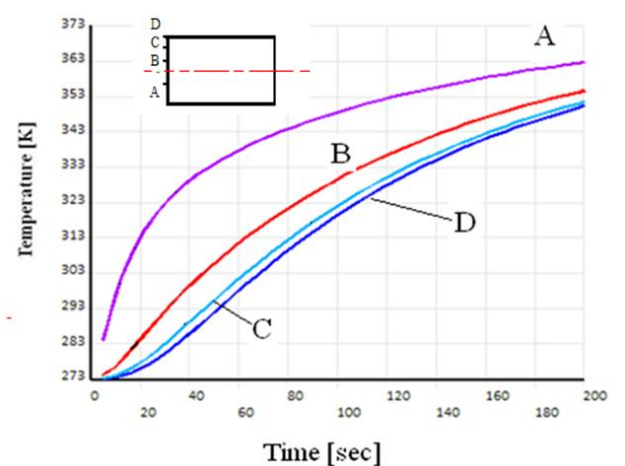

Fig. 6. Web nodal temperature through the total time interval (200sec).
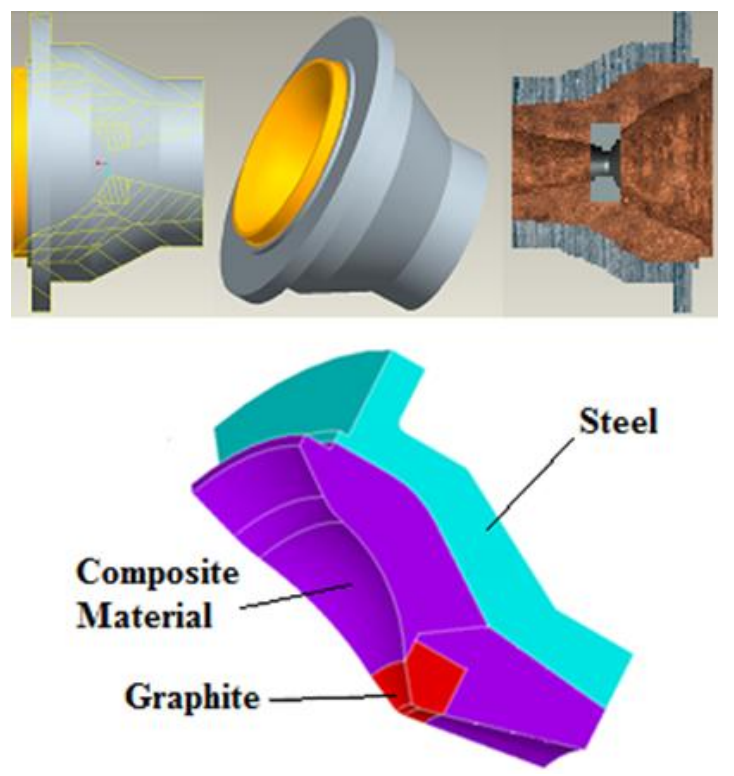

Fig. 7. 3-D section for the nozzle model.

\section{Combined (STEel AND Composite) Nozzle Model}

Thermo-structural analysis is done on the nozzle shown in Fig. 7. The nozzle consists of three substructures namely the Integral Throat e (IT) made from graphite, the composite material (Superaplast) insulator - which isolates the steel, and the main steel structure. The nozzle total length is 210 $\mathrm{mm}$, with a throat diameter of $27.8 \mathrm{~mm}$, and an expansion ratio of 6.89. The nozzle applied to loads from combustion gases, the variation of these loads along the nozzle is shown in Fig. 8 and Fig. 9 respectively. These loads obtained from thermo-chemical calculations done for this nozzle with input data for the propellant used in this motor, the output from thermo-chemical calculations are temperature and pressure along the nozzle axes.

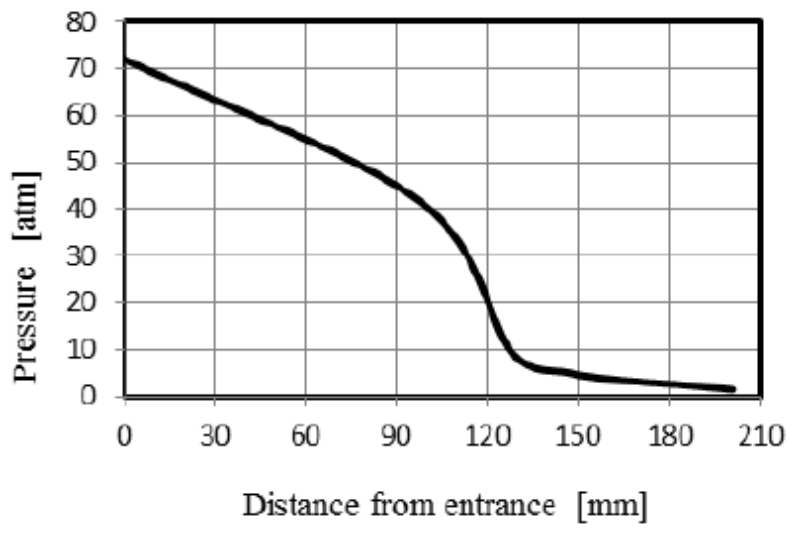

Fig. 8. Pressure along the nozzle.

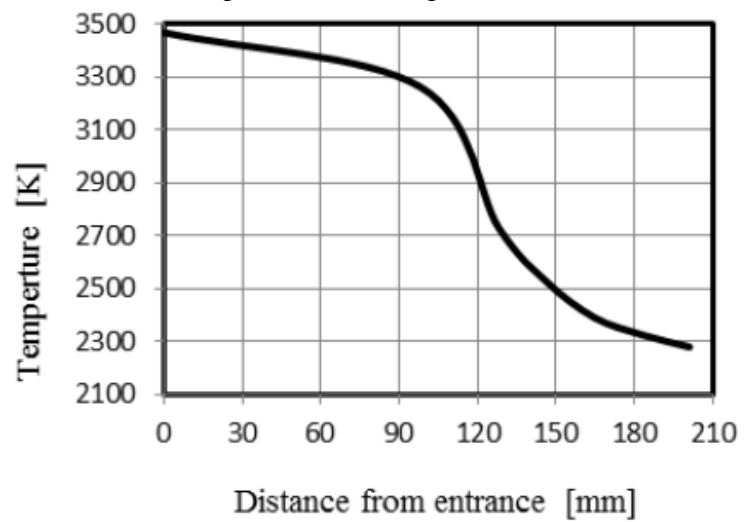

Fig. 9. Temperature along the nozzle.

\section{A. Material Properties, Loading Conditions and the Nozzle FE Model}

Since the nozzle is axially symmetric about its central axis, an axisymmetric analysis will be performed using two-dimensional, element (Plane 55) with the axisymmetric option activated. In addition, the nozzle is symmetric about a plane through the center of the cylinder. Thus, only a section of the nozzle needs to be modeled. In ANSYS, an axisymmetric model must always be created such that the global Y-axis is the axis of symmetry, and the entire model should appear on the right side of the $\mathrm{Y}$-axis (along the positive $\mathrm{X}$-axis); i.e., no part of the model (elements, nodes, etc.) may be defined with negative $X$ coordinates. Once the axisymmetric option is invoked, ANSYS will automatically apply axisymmetric boundary conditions along the Y-axis.

Material properties of the three substructures, shown in Table III, were taken to be temperature independent as a simplifying assumption [4]. The associated principle orthotropic directions correspond to a cylindrical coordinate system where $\mathrm{r}, \theta$, and $\mathrm{z}$ are represented by 3,1 , and 2 respectively. The parameters $E_{11}, E_{22}, E_{33}, G_{12}, G_{13}, G_{23}, v_{12}$, $v_{13}, v_{23}, k_{1}, k_{2}, k_{3}, \alpha_{1}, \alpha_{2}$ and $\alpha_{3}$, are the moduli of elasticity, 
shear moduli, Poison's ratios, thermal conductivities and coefficients of thermal expansion in their associated directions respectively, while $\mathrm{C}_{\mathrm{p}}$ and $\mathrm{q}$ are the materials' specific heat capacity and density respectively.

For modeling the designed nozzle, the four-node axisymmetric thermal solid "Plane 55" element was selected for the steel and the 8-node thermal solid "Plane 77" element is selected for the composite material from the ANSYS computer program element library. The four-node axisymmetric structural solid "Plane 182" element was coupled with thermal element "plane 55" for steel and the 8-node structural solid "Plane 183" element was selected for the composite material from the ANSYS computer program element library. The mode is discretized into 621 element and 1440 nodes.

In order that the two models become identical for the solution of the coupled problem, the discretized model formerly used for heat analysis must be used and the temperature distribution from the thermal analysis used as an input for the structural analysis.

The analysis of the nozzle considers a zero displacement in the axial and radial directions $\mathrm{X}$ and $\mathrm{Y}$ at the interface with the motor case. The calculated pressure is multiplied by $110 \%-120 \%$ to obtain the value of the maximum expected operating pressure MEOP. The effect of temperature on the structure is studied at chosen time instants $(1 \mathrm{sec})$ at the beginning of firing test, and at $(7 \mathrm{sec})$ at the end of burning time. Three paths are taken at the finite element model to carry out the analysis at the three different sections (entrance, throat, and exit), it's shown in Fig. 11.

TABLE III: MATERIAL PROPERTIES FOR THE NOZZLE AT ROOM TEMPERATURE

\begin{tabular}{llll}
\hline \hline parameter & graphite & composite & steel \\
\hline $\mathrm{K}[\mathrm{w} / \mathrm{m} \cdot \mathrm{k}]$ & $\mathrm{kx}=121.1$ & $\mathrm{kx}=0.5$ & 60.5 \\
& $\mathrm{ky}=69.2$ & $\mathrm{ky}=0.3$ & \\
$\mathrm{C}[\mathrm{J} / \mathrm{kg} \cdot \mathrm{k}]$ & 1046 & 1000 & 420 \\
$\rho[\mathrm{kg} / \mathrm{m} 3]$ & 1750 & 1850 & 7850 \\
$\mathrm{E}(\mathrm{GPa})$ & $\mathrm{E} 1=5.1713$ & $\mathrm{E} 1=60.67$ & 200 \\
& $\mathrm{E} 2=6.2055$ & $\mathrm{E} 2=24.82$ & \\
$v$ & $v 1=0.23$ & $v 1=0.24$ & 0.3 \\
& $v 2=0.02$ & $v 2=0.49$ & \\
$\alpha(1 / \mathrm{oK}) \times 10-6$ & $\alpha 1=2.7$ & $\alpha 1=6.3$ & 12 \\
& $\alpha 2=3.96$ & $\alpha 2=20.52$ & \\
$\mathrm{X}(\mathrm{GPa})$ & 0.031 & 1.289 & 1.241 \\
$\mathrm{X}^{\prime}(\mathrm{GPa})$ & 0.062 & 0.821 & 1.241 \\
$\mathrm{Y}(\mathrm{GPa})$ & 0.021 & 0.0462 & 1.234 \\
$\mathrm{Y}^{\prime}(\mathrm{GPa})$ & 0.069 & 0.174 & 1.234 \\
$\mathrm{~S}(\mathrm{GPa})$ & 0.021 & 0.045 & 0.752 \\
\hline \hline
\end{tabular}

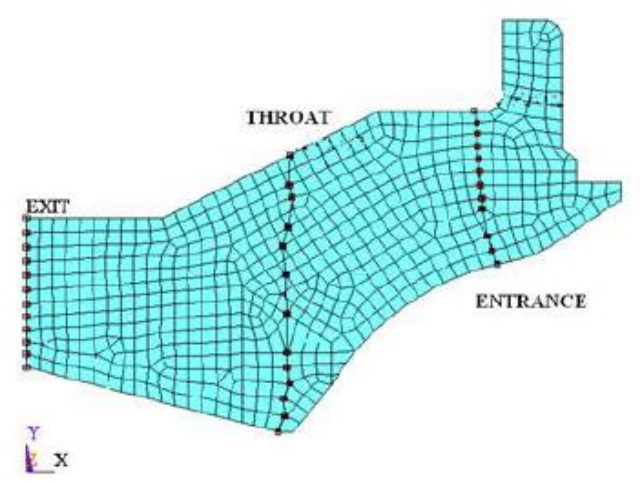

Fig. 11. Entrance, throat, exit sections.

\section{B. The Solution Procedure}

To develop a solution to such a thermo-structural problem, ANSYS employs a two stage solution scheme using a thermal and mechanical model of the problem, which results in an uncoupled thermo-structural solution. The technique is applicable to both transient (thermal) and static (structural) analyses, and the first stage entails the analysis of the thermal model, using ANSYS's thermal module. This analysis gives out the temperature distribution in the nozzle as a function of time - required by the structural model to determine the thermal strains generated by thermal loading - to be established. In the event that the thermal and structural model meshes, and solution time step formats are equivalent - such as in this case - ANSYS reports this temperature distribution by writing a temperature file to memory, with this temperature file linking the thermal analysis to the structural analysis-the latter being the second stage of the thermo-structural solution procedure. The structural model, featuring all associated mechanical loading, is then instructed to read the appropriate temperature file, and during the subsequent structural analysis, a temperature input for each node in the model is copied at each time step of the analysis. In this way, the second analysis is able to account for the effects of both the thermal and mechanical loading, and thus generate a thermo-structural solution. It should be noted that the thermal field has an effect on the stress/stain field, but no facility is made available for the stress/strain field to influence the thermal field in return.

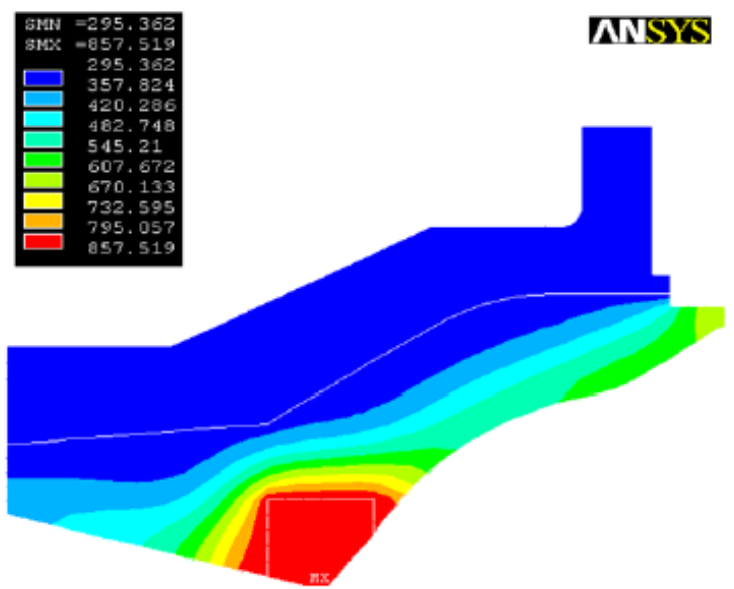

Fig. 12. Temperature distribution at time (300 s)

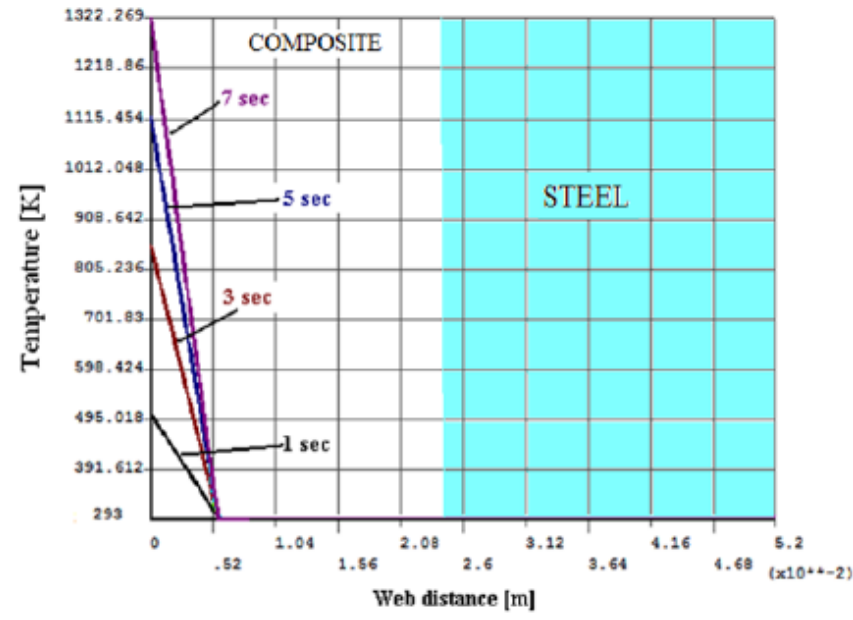

Fig. 13. Temperature history across the web thickness at exit. 


\section{RESUlTS AND DisCUSSION}

\section{A. Thermal Analysis Results}

The nozzle was subjected to thermo-structural loading for 7 seconds with incremental time step for the calculation 0.05 second. The temperature distribution in the wall thickness at time $=300$ second is shown in Fig. 12. The temperature distribution resulting from the calculation of heat transferred to the nozzle wall at different sections and times (exit and throat) are shown in Fig.13-14.

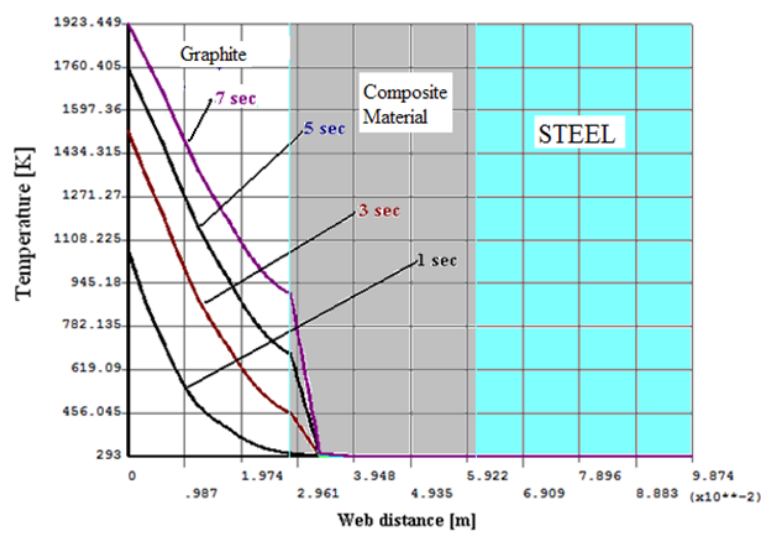

Fig. 14. Temperature history across the web thickness at throat.

It can be seen from the above figures that:

1) While the temperature of gases at throat was $3264 \mathrm{~K}$, the convective heat transfer coefficient was 2500 $\mathrm{W} / \mathrm{m}^{2} \mathrm{~K}$, after $(1 \mathrm{sec})$ the temperature at the internal surface was $1000 \mathrm{~K}$, and after $(7 \mathrm{sec})$ the temperature at the internal surface was $1923 \mathrm{~K}$

2) The temperature decreased gradually through the graphite from internal surface to distance $0.03 \mathrm{~m}$, then decreased sharply reaching the initial temperature

3) While the temperature of gases at exit was $2150 \mathrm{~K}$, the convective heat transfer coefficient was 900 $\mathrm{W} / \mathrm{m}^{2} \mathrm{~K}$, after $(1 \mathrm{sec})$ the temperature at the internal surface was $500 \mathrm{~K}$, and after $(7 \mathrm{sec})$ the temperature at the internal surface was $1323 \mathrm{~K}$.

4) The temperature decreased sharply across the wall thickness at exit until reaching $293 \mathrm{~K}$ at distance $0.006 \mathrm{~m}$.

\section{B. Thermo-structural Analysis Results}

The results of structural analysis due to pressure and thermal loads are presented in Fig. 15-20.

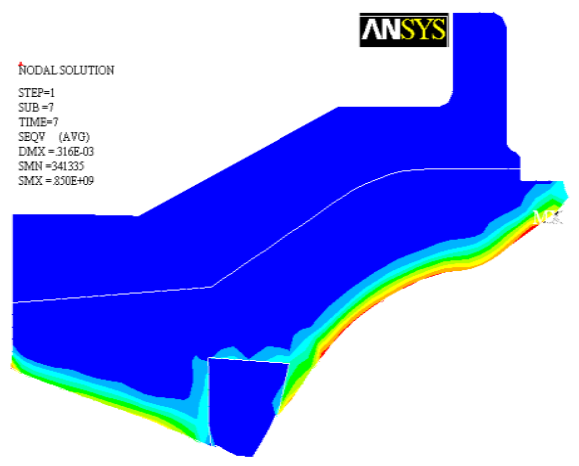

Fig. 15. Von Misses stress at time $(1 \mathrm{sec})$.
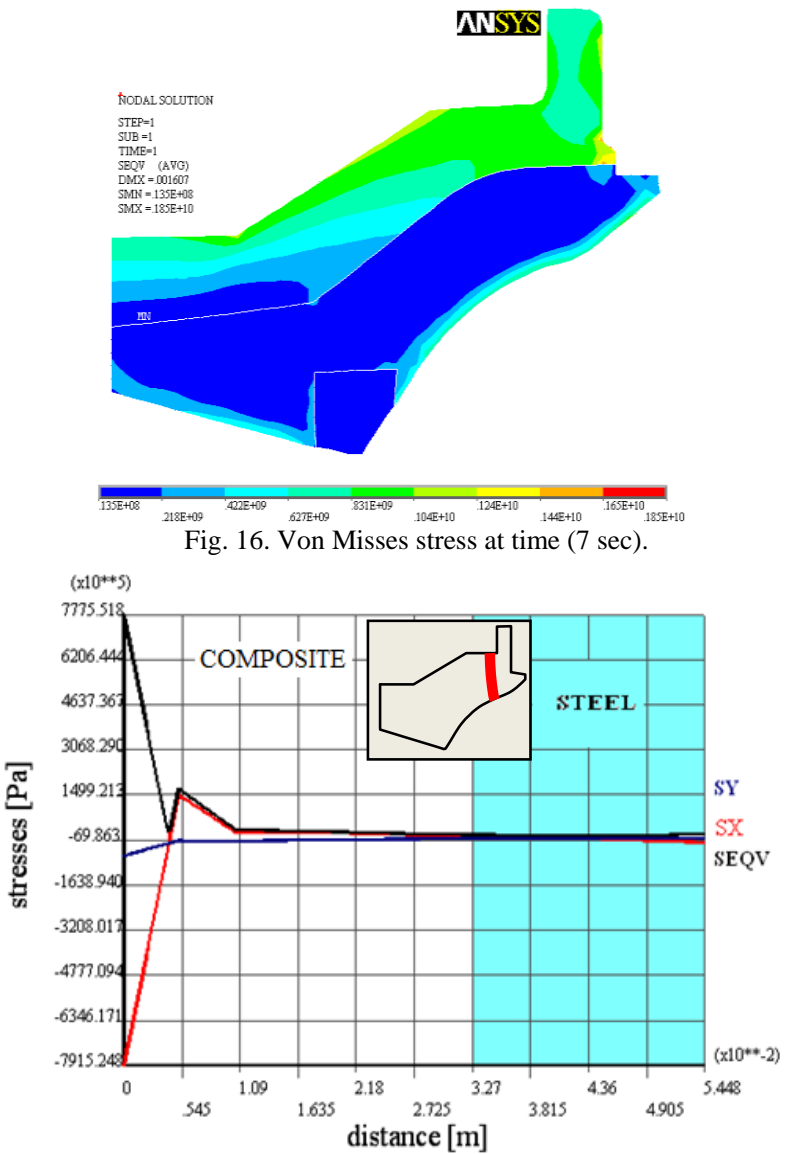

Fig. 17. Axial, radial, and Von Misses stresses at time (1 sec).

1) Fig. 19 shows the axial, radial, and Von Misses stresses at the entrance section at time ( $1 \mathrm{sec})$, it can be seen that:

- Stresses at internal nozzle wall is more than 700 $\mathrm{MPa}$, this can give an indication about how much the thermal load affects the nozzle structure.

- stresses decreased gradually in composite, and almost vanishes at distance $0.01 \mathrm{~m}$ from the internal surface

- The axial stress is having the most effectiveness in equivalent stresses than the radial stresses.

- Von Misses stress appear as tension stress at the internal surface then compression stress appears from $0.01 \mathrm{~m}$ to the steel part

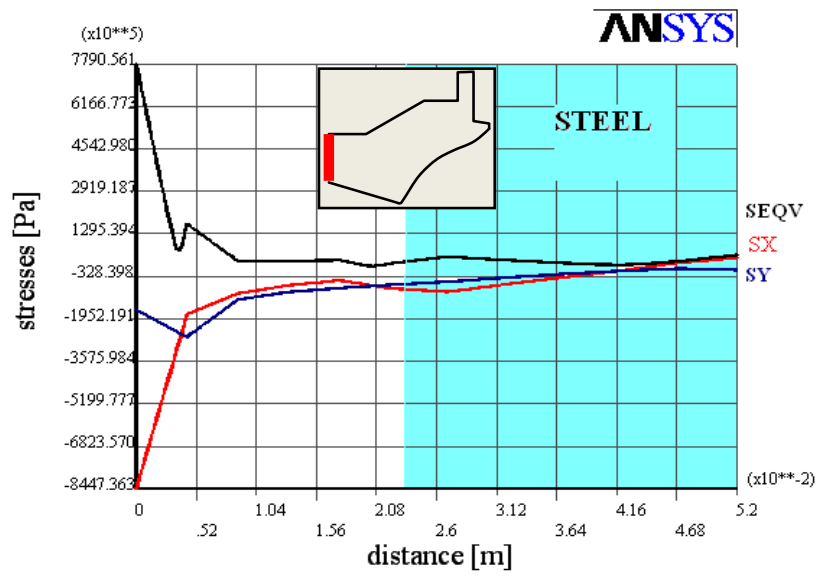

Fig. 18. Axial, radial, and Von Misses stresses at time (1 sec).

2) Fig. 18 shows the axial, radial, and Von Misses stresses 
at exit section at $(1 \mathrm{sec})$

- An elevated value of tension stresses (790 MPa) at the internal surface is seen then decreased through the composite.

- The stresses at the beginning of steel part $(0.002 \mathrm{~m})$ increased but with very small value

- With the increase of time of operation the stresses at the interface between steel and composite increased

- The radial stresses is lower than axial stresses

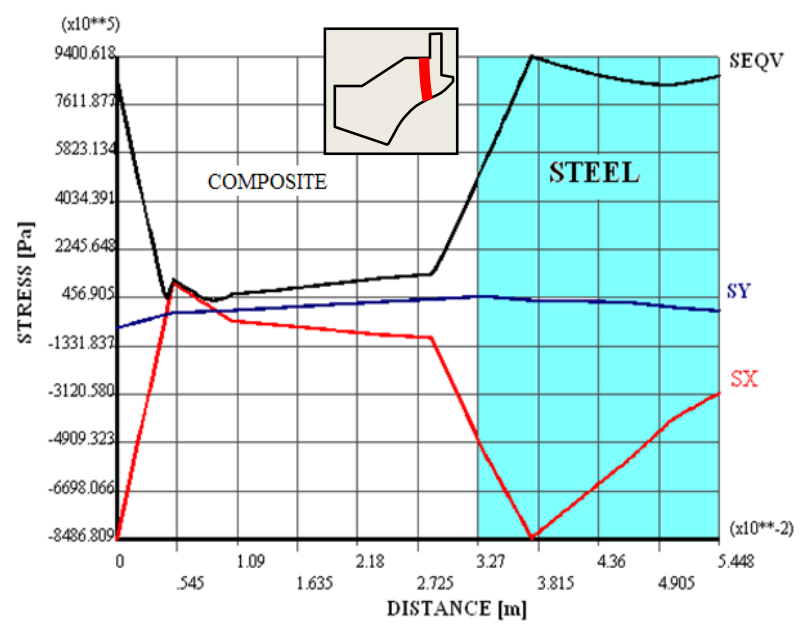

Fig. 19. Axial, radial, and von misses stresses at entrance.

3) Fig. 19 shows the axial, radial, and Von Misses stresses at the entrance section at time $(7 \mathrm{sec})$

- The thermal stresses increased with more time of operation

- The stresses begins to increase in composite part at a distance of $0.01 \mathrm{~m}$ with slow rate to became $100 \mathrm{MPa}$ at distance $0.03 \mathrm{~m}$ from the internal surface, stresses then began to increase sharply at the interface with the steel due to the rigidity of steel (elasticity of steel is lower than that of composite material)

- Stresses continue to increase in steel to reach $940 \mathrm{MPa}$ at distance $0.038 \mathrm{~m}$ then decreased slowly to the outer surface

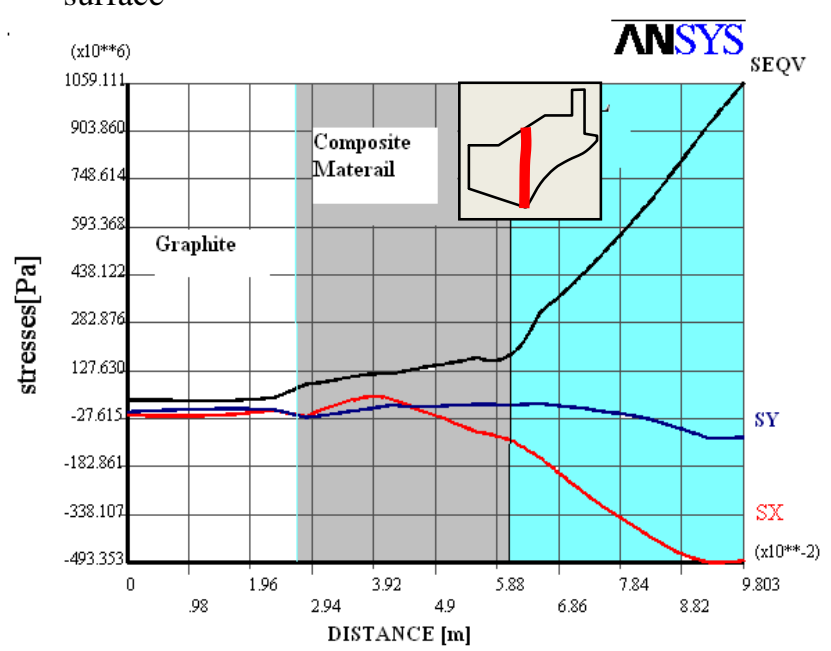

Fig. 20. Axial, radial, and Von misses stresses at throat section.

4) Fig. 20 shows the axial, radial, and Von Misses stresses at the throat section at time $(7 \mathrm{sec})$

- Due to very high thermal conductivity of graphite the temperature grows quickly in the graphite section and the thermal stresses caused by the difference in temperature were disappeared.

- Stresses then began to increase in composite part slowly to reach $180 \mathrm{MPa}$ at the end of that section

- Stresses increased sharply in steel section to reach 1059 $\mathrm{MPa}$ at the outer surface

- The difference in slope of increasing of stresses can be clearly seen between composite material and steel due to the change in elastic properties.

\section{CONCLUSION}

- The difference in temperature behavior across the wall thickness can be realized from the above figures; due to the very high thermal conductivity of graphite the distance affected by the temperature is 7 times as in the entrance and exit sections where the thermal conductivity of the composite material was very low.

- The convictive heat transfer coefficient has a great effect on the temperature transferred to the nozzle wall

- Thermal loads have a great effect in generating a huge amount of stresses on the nozzle structure (more than $60 \%$ from the total stresses on the nozzle)

- The stresses induced at time 1 second give an indication about the necessity of analysis in the beginning of operation to know the effect of thermal shock

- The effect of thermal stress is increased and can be considered as the main applied load with increasing of time

- Stresses increase rapidly in steel with a maximum value in steel due to the higher value of elastic modulus than the composite material

- At the critical section, the maximum value of stresses in the first second is at the interface between the graphite and the composite material, but the maximum value in the last second is at the steel(in the $1 \mathrm{sec}$. the thermal load effect didn't reach to the steel yet)

- At the beginning of operation time ,the maximum stresses occurred at the composite materials, but at the end of firing the maximum stresses occurred in the steel part

- The maximum value of stresses for the applied nozzle is reached at throat and the entrance section at the end of duration time.

- Using of combined (composite -steel) nozzle to withstand the combined load (thermo-structural), composite used to carrying the thermal load and the steel serve as the main framework carrying structure load.

\section{REFERENCES}

[1] N. Mukherjee and P. K. Sinha, "Thermostructural analysis of rotationally symmetric multidirectional fibrous composite structures," Computers and Structures, vol. 65, no. 6, pp. 809-817, 1997

[2] A. N. Zayed, "Thermo-structural analysis of rocket nozzle," M. Sc Thesis, Military Technical College, Cairo, Egypt, 1990.

[3] E. V. Morozov and J. F.P. P. D. L. Beaujardiere, "Numerical simulation of the dynamic thermostructural response of a composite rocket nozzle throat, " Composite Structures, 2009. 
[4] F. Alhama and A. Campo, "Network simulation of the rapid temperature changes in the composite nozzle wall of an experimental rocket engine during a ground firing test," Applied Thermal Engineering, vol. 23, pp. 37-47, 2003.

[5] F. K. Chang and Z. Kutlu, "Strength and response of cylindrical composite shells subjected to out-of-plane loading," J. of Composite Materials, vol. 23, pp. 11-31, 1989.

[6] T. C. Chen and C. C. Liu, "Inverse estimation of heat flux and temperature on nozzle throat-insert inner contour," International Journal of Heat and Mass Transfer, vol. 51, pp. 3571-3581, 2008.

[7] M. Vandenboom and S. D. Heister, "Application of advanced materials in a composite rocket nozzle," in Proc. the 34th AIAA/ASME/SAE/ASEE Joint Propulsion Conference and Exhibit, Cleveland, USA, 1998.

[8] A. B. Cozart and K. N. Shivakumar, "Stress analysis of a 3-D braided composite ablative nozzle," in Proc. the 40th AIAA/ASME/ASCE/AHS/ASC Structures, Structural Dynamics, and Materials Conference and Exhibit, AIAA/ASME/AHS Adaptive Structures Forum and AIAA Forum on Non-Deterministic Approaches, St. Louis, USA, 1999.

[9] J. S. Yoo, I. H. Cho, and C. G. Kim, "Thermoelastic analysis of a kick motor nozzle incorporating spatially reinforced composites," $J$ Spacecraft Rocket, 2003, vol. 40, no. 1, pp. 83-91.

[10] R. R. Kumar, G. Vinod, S. Renjith, G. Rajeev, M. K. Jana, and R. Hrikrishnan, "Thermo-structural analysis of composite structures," Materials Science and Engineering, pp. 66-70, 2005.
[11] S. Timoshenko and J. N. Goodyear, Theory of Elasticity, 3rd edition, McGraw-Hill, New York, 1970.

[12] Metals Handbook: Properties and Selection, ASM International, ISBN 0-87170-377-7, 1990.

[13] S. Timoshenkoand S. Woinowsky-Krieger, "Theory of plates and shells," 2nd Ed., MCGRAW-Hill Book Company

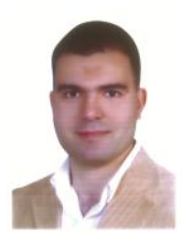

Ahmed R. Gomaa received his bachelor`s and a master`s degrees in mechanical engineering from MTC in 2004 and 2010 respectively, and he is PHD candidate in School of Astronautics, Beihang Univeristy, Beijing.

Hai Huang received his bachelor, master and Ph. D degrees of aerospace engineering in 1983, 1986 and 1990 respectively, all from Beijing University of Aeronautics and Astronautics (BUAA). His interested research areas include concept design of spacecraft, structural strength \& optimization, arms control \& space sustainability. Now he is the dean of School of Astronautics Technology, Beihang Univeristy, Beijing.BUAA. 